\title{
Frequency of incidental ocular findings during pre-employment screening at a tertiary care Eye hospital
}

\author{
Summaya Khan ${ }^{1}$, Aisha Rafique ${ }^{2}$, Omar Zafar $^{3}$
}

\begin{abstract}
Objective: To highlight the prevalence of incidentally discovered ocular findings harvested amongst candidates of different age groups presented for pre-employment screening in a tertiary care eye hospital. Methods: This Cross sectional prospective study was conducted in Armed Forces Institute of Ophthalmology, Rawalpindi, from Jun 2018 to Dec 2019. Data was collected using non-probability consecutive sampling technique. All candidates who appeared for medical fitness examination were included. Candidates belonged to various regions of Pakistan. Complete ophthalmic checkup including visual acuity, best corrected visual acuity, anterior and posterior segment examination was performed. The data analysis was done by IBM SPSS 2.0 software.

Results: One thousand and five hundred (1500) candidates underwent ophthalmic medical fitness examination during Jun 2018 to Dec 2019, out of these 86\% (1290) were males and 14\% (210) were females. Mean age of the candidates was $23.14 \pm 5.66$ years. The most common incidental ocular findings were amblyopia $24.6 \%$ (369), strabismus $10 \%$ (150), cataract 7.3\% (110), macular scar $6.5 \%$ (100) and colour vision deficiencies $5.5 \%(82)$.

Conclusion: The study demonstrates that out of total patients, $77 \%$ (1095) were found to be asymptomatic and $23 \%$ (405) were symptomatic. The study provides frequency for prevailing diseases and can help in improvement of eye care screening.
\end{abstract}

KEYWORDS: Incidental findings, Pre-employment ocular screening, Routine eye examination.

doi: https://doi.org/10.12669/pjms.37.3.3177

How to cite this:

Khan S, Rafique A, Zafar O. Frequency of incidental ocular findings during preemployment screening at a tertiary care Eye hospital. Pak J Med Sci. 2021;37(3):746-750. doi: https://doi.org/10.12669/pjms.37.3.3177

This is an Open Access article distributed under the terms of the Creative Commons Attribution License (http://creativecommons.org/licenses/by/3.0), which permits unrestricted use, distribution, and reproduction in any medium, provided the original work is properly cited.

\section{INTRODUCTION}

The incidence and prevalence of various ophthalmic diseases in a community varies with the different socio-environmental factors. The

1. Dr. Summaya Khan, FCPS.

2. Dr. Aisha Rafique, MBBS.

3. Dr. Omar Zafar, MCPS, FCPS.

1-3: Armed Forces Institute of Ophthalmology, Rawalpindi, Pakistan.

Correspondence:

Dr. Aisha Rafique, MBBS. Resident Ophthalmology, Armed Forces Institute of Ophthalmology, Rawalpindi, Pakistan.

Email: mubashir85@live.com

* Received for Publication:

* Revision Received:

* Revision Accepted:
July 1, 2020

January 25, 2021
January 4, 2021 prevalence of commonly occurring diseases are well known, at least in developed countries where public health data are collected regularly and pertinently. ${ }^{1}$ Ample valuable information has emerged from the population-based epidemiologic studies of eye disease undertaken over the past decade. Most significant finding is the negative impact that even a relatively moderate decrease in visual acuity $(<6 / 12)$ imposes on individual's quality of life and his ability to endeavor accomplishments. ${ }^{2}$ These studies have also stressed the exponential increase in ocular disorders and vision loss with advancing age. $^{3}$ This research has embarked an emphasis for the need of regular vision checkups and help practitioners to consider who is at risk among their patients in order to timely diagnose ongoing pathological process. 
In some cases, a higher prevalence of a particular disease in a population can encourage healthcare delivering administration to design an adaptable screening program aiding to implement a new treatment strategy. It aims towards decreasing morbidity and shrink disease-associated costs. In all these cases, education of high risk patients or those having a familial history of ocular disease may prompt early detection, limiting the costs necessary to treat advance stages of disease. ${ }^{4}$ Besides all conditions mentioned above, the prime manifesto is prevention of visual loss, the privileged sense of all living beings.

The key constituent of improving eye health is need for regular eye checkups, as many eye diseases can exist and progress relentlessly without the individual being aware of the problem until much vision is lost. ${ }^{5}$ Glaucoma is a classic example of such kind. It can be well diagnosed in time by prompt screening and follow up. ${ }^{6}$

In our study, incidental ocular findings in individuals who were otherwise healthy helped in the recognition that reduced vision can have a serious impact in terms of morbidity. It lays an emphasis on psycho-social issues when there was rejection of young individual right at the initial stages of pre-employment screening. It also serves as a medium of public health message regarding decreased vision from various etiological factors. Our study provides information to protect eyes from damaging effects of UV rays, pre emptive glaucoma screening and need of paying significant attention any visual symptom.

\section{METHODS}

This study was conducted over a period of one and a half year from June 2018 till December 2019 in Armed Forces Institute of Ophthalmology after taking approval from hospital ethical review committee (ERC-250/AFIO). In this cross-sectional study, a total of 1500 participants were included using non probability consecutive sampling technique. Sample size was calculated using WHO sample size calculator, keeping confidence interval of $95 \%$ and $5 \%$ error.

The study included all candidates appearing for pre-employment ocular examination. Individuals with history of any ocular surgery or neurosurgery, trauma, systemic medication that has ocular side effects like anti-tuberculosis treatment or central nervous system drugs and previous history of intra ocular injections were excluded from the study. Patient demographic data such as age, gender and place of referral were noted. Medical history including diabetes mellitus, hypertension, and other systemic diseases was documented. Informed consent was taken and they were briefly described about examination and purpose of study. Ophthalmic examination included unaided vision and best corrected visual acuity. High refractive error and amblyopia was ruled out during refraction. Individuals with -6.00 to +6.00 $\mathrm{D}$ refractive error were considered to have high myopia or high hypermetropia respectively. ${ }^{7}$ High astigmatism was considered with error of $4 \mathrm{D}^{8}$ Amblyopia was defined as unilateral or bilateral decrease in best corrected visual caused by form vision deprivation or faulty binocular interaction in absence of identifiable organic ocular pathology. ${ }^{9}$ Extraocular movements and adnexal / orbital examination was performed to evaluate proptosis which was further confirmed by using Hertels exoophthalmometer. Detailed anterior and posterior segment examination was performed via slit lamp (Haag-Streit BM 900 Unit LED Slit lamp). Intra ocular pressure measured (IOP) with air puff tonometer (Nidek NT-530/510). $>21 \mathrm{~mm}$ of Hg was confirmed with Goldman applanation tonometer. It was further supplemented with central corneal thickness measurement, optic disc evaluation, visual fields, optical coherence tomography of retinal nerve fiber layer to diagnose glaucoma or glaucoma suspects.

Detailed funduscopy using $90 \mathrm{D}$ lens and by indirect ophthalmoscope for peripheral retinal evaluation was performed. Pertinent investigations were performed to confirm suspected relevant conditions. Color vision deficiency was checked by using pseudo-isochromatic Ishihara color plates which were shown to patient monocularly at a distance of $75 \mathrm{~cm}$ in well illuminated ambience. Colour vision was checked after full correction of refractive error. Plates were presented at least for 6 to 12 seconds and candidates were asked to identify numbers or patterns of test plates. ${ }^{10,11}$

Data was entered and analyzed in SPSS version 2.0. Descriptive statistics were used to calculate mean and standard deviation of age. Percentage and frequency was calculated for prevalent ocular findings.

\section{RESULTS}

One thousand and five hundred (1500) candidates underwent ophthalmic medical fitness examination during Jun 2018 to Dec 2019, out of these 1290 (86\%) were male and $210(14 \%)$ were female. Mean age of the candidates was $23.14 \pm 5.66$ years (Table-I). 
Table-I: Age and Gender Distribution.

\begin{tabular}{lcc}
\hline \multicolumn{3}{c}{ Age Distribution } \\
\hline Age Group - Years & No. of Cases & Percentage (\%) \\
\hline $10-20$ & 615 & 41 \\
$21-30$ & 517 & 34.5 \\
$31-40$ & 270 & 18 \\
$41-50$ & 98 & 6.5 \\
\hline \multicolumn{3}{c}{ Gender Distribution } \\
\hline Males & 1290 & 86 \\
Females & 210 & 14 \\
Total & 1500 & 100 \\
\hline
\end{tabular}

The most common incidental ocular findings were amblyopia $24.6 \%$ (369), strabismus $10 \%$ (150), cataract $7.5 \%$ (110), macular scar $6.5 \%$ (100) and colour vision deficiencies $5.5 \%$ (82) (Table-II). Out of total patients, $73 \%$ (1095) were found to be asymptomatic and $27 \%(405)$ were symptomatic.

\section{DISCUSSION}

Vision is extremely treasured sense as we remark maximum imprints of our world by means of sight. It is the utmost researched sense than any other sensory modality. Intention for this is seemingly simple: because vision is most significant and intricate sense. ${ }^{12}$ Those who are agonized from visual impairment are more prone to be unemployed, socially isolated and dependent as age passes by. In our country with financial constrain, very few people have access to or have information regarding low vision rehabilitation centers. Girls suffering from syndromic low vision are not even allowed to be sent to visual rehabilitation schools owing to social stigma in certain regions of Pakistan. It supplements profound psychological and social implications. ${ }^{13}$

Our study reveals that regular comprehensive eye checkups are the best way to detect pathology for asymptomatic and symptomatic patients. It deems to devise timely preventive and curative treatment strategies. Several disorders like cataract, glaucoma amblyopia and macular degeneration are often asymptomatic or symptoms are not well appreciated by the patient at time of initial presentation. Ophthalmologists acknowledge that aforementioned disease processes are preventable and curable if identified at an early phase in disease progression. ${ }^{14}$

There were significant number of patient with amblyopia which was shockingly more
Table-II Incidence of Various Eye Diseases.

\begin{tabular}{|c|c|c|c|}
\hline $\begin{array}{l}\text { Serial } \\
\text { No }\end{array}$ & Diagnosis & $\begin{array}{l}\text { No of } \\
\text { Cases }\end{array}$ & $\begin{array}{l}\text { Percent- } \\
\text { age }(\%)\end{array}$ \\
\hline 1 & Amblyopia & 369 & 24.6 \\
\hline 2 & Strabismus & 150 & 10 \\
\hline 3 & Cataract & 110 & 7.5 \\
\hline 4 & Macular Scar & 100 & 6.5 \\
\hline 5 & Colour Vision Defect & 82 & 5.5 \\
\hline 6 & Corneal Opacity & 75 & 5.0 \\
\hline 7 & Retinal Degeneration & 66 & 4.4 \\
\hline 8 & Corneal Dystrophy & 60 & 4.0 \\
\hline 9 & Trachoma & 50 & 3.3 \\
\hline 10 & High Refractive Error & 50 & 3.3 \\
\hline 11 & Pterygium & 50 & 3.3 \\
\hline 12 & Allergic Conjunctivitis & 50 & 3.3 \\
\hline 13 & Keratoconus & 45 & 3.0 \\
\hline 14 & Presbyopia & 42 & 2.8 \\
\hline 15 & Retinochoroidal Coloboma & 25 & 1.7 \\
\hline 16 & Uveitis & 25 & 1.7 \\
\hline 17 & Glaucoma & 25 & 1.7 \\
\hline 18 & Ptosis & 25 & 1.7 \\
\hline 19 & Proptosis & 25 & 1.7 \\
\hline 20 & Nystagmus & 25 & 1.7 \\
\hline 21 & Refractive Surgery & 17 & 1.1 \\
\hline 22 & Optic Disc Drusen & 14 & 0.93 \\
\hline 23 & Posterior Staphyloma & 7 & 0.46 \\
\hline 24 & Retinal Detachment & 5 & 0.33 \\
\hline 25 & Contact Lens & 4 & 0.26 \\
\hline 27 & Episcleritis / Scleritis & 4 & 0.3 \\
\hline Total & & 1500 & 100 \\
\hline
\end{tabular}

than prevalence in other studies on Eastern population. ${ }^{15}$ Most of them were well above the age of neuroplasticity and has never undergone occlusion therapy or any other treatment modality for amblyopia. Neuroplasticity is capability of brain to reorganize its neuronal pathways. However, there is a certain age limit beyond which this remapping of neuronal mechanism is not possible. The reason for increased prevalence of amblyopia noted in our study $(24.6 \%)$ may be attributed to higher age groups participating in our study which is comparable to results of study undertaken by Hamid S et al which was $22.7 \% .{ }^{16}$ These untreated patients can have significant visual impairment persisting throughout their lives. 
Cataract is a leading cause of reversible blindness. ${ }^{17}$ In our study cataract was also recognized as a significant incidental finding. Most of the candidates in our study were asymptomatic. It included blue dot, sutural, posterior polar and lamellar cataract affecting mild to moderate vision loss of $<6 / 12$. Over the time these patches of lenticular opacity become bigger and blurry eventually leading to marked visual loss. ${ }^{18}$

Keratoconus prevalence in our population is comparable to results of the international data. Main assosciation is vernal kerato-conjunctivitis in all the individuals. Keratoconus is considered as debilitating visual pathology and considered as disease of a young population. Steepening and thinning of cornea in keratoconus is associated with sight threatening complications. Treatment ranges from spectacles to expensive advance refractive procedures. ${ }^{19}$

There were 50 patients out of 1500 who had pterygium and all of them were males. Some of them deployed or were residents at higher altitudes leading to implication of increased solar exposure. Patient were educated regarding the disease and treatment which entails surgical removal if it obscures visual axis.

Prevalence of high refractive error was 3.3 percent. It is comparable to other published studies. ${ }^{20}$ Myopia was found as most common high refractive error $(64.5 \%)$, high hypermetropia $(21 \%)$ and high astigmatism $(14.5 \%)$. Astigmatism was found to be most common refractive error $(68.6 \%)$. High myopia is associated with retinal degenerations and premature posterior vitreous detachment leading to symptomatic break in retina. ${ }^{21}$ These entities demand urgent surgical repair with ensured availability of advance instrumentation and expertise which if not timely undertaken leads to total blindness. ${ }^{22}$ Prevalence of corneal opacities varies with one region of world to another. Main causes identified were trauma, road traffic accident, trachoma and miscellaneous infectious etiology. ${ }^{23}$

Strabismus is associated with short term (diplopia, headache, confusion) and long term effects (abnormal or absent binocular vision, unacceptable cosmesis). ${ }^{24}$ Frequency of strabismus in our study group is comparable to national data. Most common strabismus was eso-deviation under less than 20 years of age group (1.7\%). According to different surveys, eso-deviation is approximately three times common in children and younger age groups. However, exo-deviation is more common in age group greater than 20 years (3.3\%). ${ }^{25}$ Majority of cases were manifest strabismus in our study.
One entity worth mentioning is raised frequency of color blindness found among individual. Out of these, $94.52 \%$ were absolutely unaware of their anomalous visual status. It is comparable to other research study undertaken in southern Punjab province of Pakistan which showed prevalence of $93.54 \% .{ }^{26}$ Although it is non pathological, nonprogressive and incurable, it poses major risk in rejection for specified jobs like aviation, defense, railway employment in younger population striving and pursuing for their livelihood.

Allergic conjunctivitis is an all-encompassing term that comprises of seasonal allergic conjunctivitis, worsening with seasonal variations, vernal keratoconjunctivitis which has established connotation in development of keratoconus and atopic keratoconjunctivitis which exacerbates on exposure to specific recognized antigen. ${ }^{27}$ In our study, 3.3 percent had allergic conjunctivitis. Most had mild symptoms.

One of the significant finding is presence of atrophic macular scar $(6.5 \%)$, the prevalence is comparable to internationally published study by Machado RAF et al which was $6.38 \% .^{28} 98 \%$ were healed associated with trauma in childhood and toxoplasmosis. Atrophic scars present in foveal region severely compromised central visual field and almost all patient with foveal scar having central visual field defects.

There were $73 \%$ of asymptomatic and $27 \%$ symptomatic patients. These asymptomatic patients were incidentally found thorough ophthalmic examination harboring pathology or at least having risk of developing pathology warranting necessity of treatment and follow up. Our study, which was conducted in a particular proportion of population has emphasized on the fact that percentage of incidental findings observed during pre-employment screening if extrapolated to total no of patients visiting for routine eye examination, the resultant number of affected individuals would be substantially high.

Limitation of the study: Our study was limited as only those patients who had ocular findings were included. So systemic associations couldn't be found. However, these patients were further referred to specialized clinics for treatment and visual rehabilitation.

\section{CONCLUSION}

Our study has given us insight that ocular examination is much more than mere refraction and prescription of glasses as believed by our 
general population. It has provided a scaffold in identification of ocular diseases. It is demonstrated to expedite incidental findings as harbinger for necessary referral and timely intervention to prevent vision loss.

Conflict of Interest: This study has no conflict of interest to declare by any author.

\section{Grant Support E Financial Disclosures: None.}

\section{REFERENCES}

1. Dobbelsteyn D, McKee K, Bearnes RD, Jayanetti SN, Persaud $\mathrm{DD}$, Cruess AF. What percentage of patients presenting for routine eye examinations require referral for secondary care? A study of referrals from optometrists to ophthalmologists. Clin Exp Optom. 2015;98(3):214-217. doi: 10.1111/cxo.12255

2. Wong TY, Hyman L. Population-based studies in ophthalmology. Am J Ophthalmol. 2008;146(5):656-663. doi: 10.1016/j.ajo.2008.07.048

3. Umfress AC, Brantley MA Jr. Eye Care Disparities and Health-Related Consequences in Elderly Patients with AgeRelated Eye Disease. Semin Ophthalmol. 2016;31(4):432-438. doi: 10.3109/08820538.2016.1154171

4. Baranwal VK, Avinash M, Vivek S, Sandeep G, Shyam $S$, Sudheer V. The Prevalence of Various Eye Diseases Among Patients of Different Nationalities attending the Ophthalmology Clinic at a Tertiary Care United Nations Hospital: A 5 Year Retrospective Analysis. Int J Contemp Med Res. 2019:6(9):17-20. doi: 10.21276/ijcmr

5. Yadav S, Tandon R. Comprehensive eye examination: what does it mean? Community Eye Health. 2019;32(107):S1-S4.

6. Weinreb RN, Aung T, Medeiros FA. The pathophysiology \& treatment of glaucoma: A review. JAMA. 2014;311:1901-1911.

7. High Refractive Error. [cited 2020Jun27]. Available from: https://www.aao.org/bcscsnippetdetail.aspx?id=5fbc7fa8e5d4-42d5-9e6d-eae8504dbc54

8. Refractive Errors and Vision Correction Surgery Dallas Fort Worth [Internet]. Cornea Associates of Texas of Texas. [cited 2020Jun27]. Available from: https://www.corneatexas. com/about/eye-info/refractive-errors

9. Salmon JF. Kanski's Clinical Ophthalmology: A systematic approach. $9^{\text {th }}$ ed. London. Elsevier. 2020. Chapter 18, Strabismus, $\mathrm{p} 707$

10. HM Elflein, S Fresenius, J Lamparter, S Pitz, N Pfeiffer, H Binder, et al. The prevalence of amblyopia in Germany: data from the prospective, population-based Gutenberg Health Study. Deutsches Arzteblatt Int. 2015;112(19):338-344.

11. Kass MA, Heuer DK, Higginbotham EJ, Johnson CA, Keltner JL, Miller JP, et al. The Ocular Hypertension Treatment Study: a randomized trial determines that topical ocular hypotensive medication delays or prevents the onset of primary open-angle glaucoma. Arch Ophthalmol. 2002;120(6):701.

12. Rados C. A focus on vision. FDA Consum. 2006;40(4):10-17.

13. Negiloni K, Ramani KK, Jeevitha R, Kalva J, Sudhir RR. Are children with low vision adapted to the visual environment in classrooms of mainstream schools? Indian J Ophthalmol. 2018;66(2):285-289.

14. Samy EL, Gendy NM, Abdel-Kader AA. Prevalence of Selected Eye Diseases Using Data Harvested from Ophthalmic Checkup Examination of a Cohort of Two Thousand Middle Eastern and North African Subjects. J Ophthalmol. 2018;2018:8049475. doi:10.1155/2018/8049475
15. Chen X, Fu Z, Yu J, Ding H, Jing B, Ji C, et al. Prevalence of amblyopia and strabismus in Eastern China: results from screening of preschool children aged 36-72 months. Br J Ophthalmol. 2016;100(4):515-519. doi: 10.1136/ bjophthalmol-2015-306999

16. Hamid S, Javadi A, Rafati N. Prevalence and causes of low vision and blindness in Tehran Province, Iran. J Pak Med Assoc. 2011;61(6):544-549.

17. Flaxman SR, Bourne RRA, Resnikoff S, Ackland P, Braithwaite T, Cicinelli MV, et al. Global causes of blindness and distance vision impairment 1990-2020: a systematic review and meta-analysis. Lancet Glob Health. 2017;5(12):e1221-e1234. doi: 10.1016/S2214-109X(17)30393-5

18. Kozarsky A. Corneal Opacities: Eye Disorders That Can Cause Vision Loss [Internet]. WebMD. WebMD; 2018 [cited 2020Jun24]. Available from: https://www.webmd.com/ eye-health/corneal-opacities

19. Sharif R, Bak-Nielsen S, Hjortdal J, Karamichos D Pathogenesis of Keratoconus: The intriguing therapeutic potential of Prolactin-inducible protein. Prog Retin Eye Res. 2018;67:150-167. doi: 10.1016/j.preteyeres.2018.05.002

20. Hashemi H, Fotouhi A, Yekta A, Pakzad R, Ostadimoghaddam H, Khabazkhoob M. Global and regional estimates of prevalence of refractive errors: Systematic review and meta-analysis. J Curr Ophthalmol. 2018;30:3-22. doi: 10.1016/j.joco.2017.08.009

21. Saw SM, Gazzard G, Shih-Yen EC, Chua WH. Myopia and associated pathological complications. Ophthalmic Physiol Opt. 2005;25:381-391.

22. Hugh R. Hien T, TVVu Catherine, McCarty A, Jill E. Keeffe; The Need for Routine Eye Examinations. Invest. Ophthalmol Vis Sci. 2004;45(8):2539-2542. doi: 10.1167/iovs.03-1198

23. Moore BA, Roux MJ, Sebbag L, Cooper A, Edwards SG, Leonard BC. A population study of common ocular abnormalities in C57BL/6N rd8 Mice. Invest Ophthalmol Vis Sci. 2018;59(6):2252-2261. doi: 10.1167/iovs.17-23513

24. Hernandez Martinez P, Rodriguez Del Valle JM. Strabismusassociated myopia. Review. Revision del estrabismo en miopes. Arch Soc Esp Oftalmol. 2017;92(12):585-593. doi: 10.1016/j.oftal.2017.06.007

25. Michaud L, Forcier P. Prevalence of asymptomatic ocular conditions in subjects with refractive-based symptoms. J Optom. 2014;7(3):153-160. doi: 10.1016/j.optom.2013.08.003

26. Fatima N, Munawar T, Fatima T. Frequency of color blindness amongst the youngest age group in southern Punjab province of Pakistan. Pak Armed Forces Med J. 2018;68(5):1190-1193.

27. Bielory L, Delgado L, Katelaris $\mathrm{CH}$, Leonardi A, Rosario N, Vichyanoud P. ICON: Diagnosis and management of allergic conjunctivitis. Ann Allergy Asthma Immunol. 2020;124(2):118-134. doi: 10.1016/j.anai.2019.11.014

28. Machado RAF, Bortolli JP, Bassanezi F. Prevalence of chorioretinal scars in angiographics exams. Rev Bras Oftalmol. 2016:75(2): doi: 10.5935/0034-7280.2016002

\section{Author's Contribution:}

SK: Conceived, data collection and is responsible for integrity of the study.

AR: Data collection, statistical analysis and manuscript writing.

OZ: Review and final approval. 